Revista Eletrônica em Gestão, Educação e Tecnologia Ambiental Santa Maria, v. 20, n. 1, jan.-abr. 2016, p. 86-96

Revista do Centro de Ciências Naturais e Exatas - UFSM

ISSN : 22361170

\title{
O processo de aprendizagem organizacional em central cooperativa agroindustrial
}

\section{The organizational learning process in a agribusiness cooperative central}

\author{
Douglas Royer ${ }^{1}$, Frederico Fonseca da Silva ${ }^{2}$ e Estanislau Gonçalves Jovtei ${ }^{3}$ \\ ${ }^{1}$ Mestre em Administração pela Universidade Estadual de Londrina (UEL), Londrina, PR, Brasil \\ 2 Doutor e Mestre em Agronomia pela Universidade Estadual de Maringá (UEM), Maringá, PR, Brasil \\ ${ }^{3}$ Mestre em Engenharia de Produção pela Universidade Federal de Santa Catarina (UFSC), Florianópolis, SC, Brasil
}

\begin{abstract}
Resumo
Para analisar o processo da aprendizagem organizacional em central cooperativa agroindustrial à luz do modelo OADI-SMM, sob a perspectiva da organização tendo o cooperado como indivíduo, o constructo do estudo partiu das seguintes premissas: compreender os principais conceitos sobre aprendizagem organizacional e o modelo OADI-SMM; compreender as peculiaridades das organizações cooperativistas no agronegócio e suas principais características de gestão; compreender o processo da aprendizagem organizacional em central cooperativa agroindustrial, seus principais mecanismos, agentes e momentos; analisar à luz do modelo OADI-SMM o processo da aprendizagem na unidade de estudo e possíveis rupturas na aprendizagem organizacional. A análise dos materiais se deu a partir da interpretação, da contextualização e da atenção aos detalhes e às experiências dos entrevistados. Apurou-se que a Cooperativa Central tem desenvolvido e fortalecido contínua e endemicamente os seus mecanismos de aprendizagem organizacional e, como forma de fazer frente à complexidade do agronegócio, tem conseguido promover a troca dos conhecimentos adquiridos nas adaptações ao ambiente. A principal constatação deste Estudo de Caso é de que a Cooperativa Central consegue promover a transferência da aprendizagem entre o indivíduo e a organização, portanto, realmente aprende.
\end{abstract}

Palavras-chave: Gestão. Conhecimento. Cooperativismo. Agronegócio. OADI-SMM.

\begin{abstract}
To analyzing the process of organizational learning in central agribusiness cooperative in the light of OADI-SMM model, from the perspective of the organization having cooperated as an individual, the study of construct left the following assumptions: understand the main concepts of learning organizational and OADI-SMM model; understand the peculiarities of cooperative organizations in agribusiness and its main features management; understand the process of organizational learning in central agribusiness cooperative, its main engines, agents and moments; analyzing the light of OADI-SMM model the process of learning in the unit of study and possible disruptions in organizational learning. With the interpretation of context and attention to detail and the experiences of respondents, it can be concluded in the study that, over time, the Central Cooperative has developed and strengthened continuously and endemically their organizational learning mechanisms and as a way to cope with the complexity of agribusiness, has been able to promote the exchange of knowledge acquired in adaptations to the environment. The main finding of this case study is that the Central Cooperative can promote the transfer of learning between the individual and the organizational, so we really learn.
\end{abstract}

Keywords: Management. Knowledge. Rural. OADI-SMM. 
Royer et al.: O processo de aprendizagem organizacional em central cooperativa agroindustrial

\section{Introdução}

A capacidade da cooperativa, enquanto organização, em se estruturar como um sistema de aprendizagem (LEONARD-BARTON, 1992) colabora com a construção de uma estratégia mais dinâmica e pertinente ao cenário competitivo atual (GHEMAWAT, 1991), que é acentuada no agronegócio, escolhido como ambiente para este estudo, se apresentando como um loco interessante para a atenção à aprendizagem organizacional enquanto uma possível fonte da inovação incremental dessas organizações, não se restringindo aos limites do agronegócio ou mesmo da firma, porque, segundo Powell (1990), as fontes de inovação por vezes se encontram na intersecção entre universidades, laboratórios de pesquisa, fornecedores, clientes e entre as próprias organizações.

Essas organizações agroindustriais têm participação significativa na economia brasileira, seja na geração de empregos ou no desempenho da balança comercial, bem como, sofrem impactos diretos no caso de alterações nos cenários políticos e econômicos, nacionais ou internacionais, principalmente se considerarmos que, atualmente, os mercados internacionais e as economias nacionais modernas caracterizam-se pela marcante presença da inovação para a manutenção da competitividade.

Além da força produtiva e econômica, a opção por uma cooperativa central agroindustrial como unidade de estudo se estabelece pela complexidade de um sistema cooperativista verticalizado enquanto uma organização, uma vez que tanto para a criação quanto para a consolidação de organizações cooperativistas depende-se do fomento de um sistema auxiliar para ampliar a dinamicidade das capacidades sociais e produtivas nas comunidades rurais, buscando promover o desenvolvimento enquanto um processo no qual a inclusão social e produtiva seria um dos aspectos fundamentais para alcançar o fortalecimento e utilização do capital social existente por meio do sistema cooperativista, envolvendo pequenos e médios produtores rurais para melhorar a qualidade de vida dos indivíduos por meio do aumento da renda e ganho de sinergia produtiva da rede, isto é, expansão da cooperativa e inclusão dos cooperados na gestão. No estudo, busca-se compreender, à luz do modelo OADI ${ }^{1}-\mathrm{SMM}^{2}$ de Kim (1993), os fatores envolvidos na aprendizagem organizacional em um sistema agroindustrial cooperativista verticalizado, onde a construção de conhecimentos e a inovação tecnológica têm desencadeado mudanças na gestão da propriedade rural e no agir por parte dos cooperados e das cooperativas.

\section{As organizações cooperativistas}

As cooperativas, em acordo com a legislação, são organizações responsáveis por uma atividade econômica voltada ao proveito comum e que não tem objetivo de lucro, onde a adesão deve ser livre, o capital é representado em quotas partes, o voto é único, existe retorno as chamadas sobras líquidas, entre outros pontos específicos. Em função das características peculiares, para Waack e Machado Filho (1999), a gestão estratégica das cooperativas pode ser mais complexa do que para outras organizações. Pois, em geral, a propriedade e o controle não estão dissociados, os cooperados geralmente são os gestores e na maioria das vezes clientes e fornecedores, além de serem proprietários das mesmas, o que pode ocasionar conflitos internos. A força política de cada cooperado, em função do peso de seu voto, pode dificultar o processo de tomada de decisão, pois, a não homogeneidade de interesses pode acarretar problemas de falta de foco nos negócios e de escala.

Outro aspecto importante é o fato que a venda da produção pode representar um retorno financeiro superior à distribuição de lucros, por este motivo, geralmente, não existe um acompanhamento efetivo das ações dos gestores por parte dos cooperados. Esta complexidade na gestão estratégica, considerando-se a Nova Economia Institucional como base para análise das cooperativas, pode apresentar pelo menos cinco problemas (COOK, 1995): Problema de horizonte uma vez que os cooperados tendem a buscar retornos de curto prazo, pois o capital não pode ser

${ }^{1}$ OADI - The Observe-Assess-Design-Implement.Em português: Observar, Avaliar, Projetar, Implementar

${ }^{2}$ SMM - Shared Mental Models. Em português: Modelos Mentais Compartilhados 
Royer et al.: O processo de aprendizagem organizacional em central cooperativa agroindustrial

vendido a terceiros e os novos cooperados se beneficiam dosantigos, sem vantagens para continuar investindo; Problema de incentivo - alguns cooperados podem focar apenas na comercialização, sem manter uma participação efetiva na cooperativa; Problema de portfólio - a falta de visão de longo prazo bloqueia investimentos em tecnologia, marketing e distribuição, o que pode impossibilitar a agregação de valor no produto e serviços das cooperativas; Problema de controle - a partir do aumento da complexidade das operações em uma cooperativa, a falta de acompanhamento por parte dos associados pode ser crítica; Problemas de influência - coalizões políticas internas para a ascensão a cargos executivos pode levar um grupo a se manter no poder e/ou defender os interesses próprios.

Para contornar seus principais problemas Cook (1995), diz que as cooperativas procuram estabelecer políticas que estimulem a fidelidade do cooperado, promovendo a utilização de seus serviços, a participação na gestão e capitalização da governança. Por estes meios, procura-se resgatar o compromisso, a participação e a capitalização de tudo que os cooperados aportam nas cooperativas.

Procura-se, também, segundo Chadad (2007), controlar o oportunismo de se utilizar a cooperativa somente quando tiver o menor preço. Por isso, as cooperativas se valem da comunicação para a fidelidade do cooperado, a partir de estruturas especializadas no relacionamento, cujos investimentos são controlados em centros de custos específicos, transmitindo a mensagem de que o cooperado tem voz e que o mesmo pode exercer sua influência nas decisões da cooperativa (ibidem). Ainda segundo o autor, outra forma adotada para controle dos oportunistas são os contratos de comercialização, alinhada a tendência atual de manter um quadro de associados fechados onde o acordo contratual é uniforme e passível de monitoração e execução legal.

Estas peculiaridades impõem uma gestão profissionalizada às cooperativas, que ao longo do tempo tem se aperfeiçoado (POLÔNIO, 1999), sendo constituída geralmente por um Conselho de Administração, o qual supervisiona a direção executiva ou gerência funcionando como um órgão executivo na gestão cooperativista, e por um Conselho Fiscal, que audita os atos do Conselho de Administração acompanhando aspectos econômico-financeiros e se reportando exclusivamente à Assembleia Geral. A Assembleia Geral representa bem o caráter de perenidade da organização cooperativa que, conforme Pedrozo (1993), enquanto sociedade é composta por um grupo de indivíduos com os mesmos interesses, cuja união viabiliza a consecução de tarefas, promove o progresso e gera bem-estar aos cooperados, detentores da propriedade da organização.

No cooperativismo duas lógicas distintas se apresentam numa mesma organização: a econômica e a social (PEDROZO, 1993). Lauschner (1995), sintetiza o modelo de gestão cooperativa como aquele que tem caráter econômico e social tendo com premissa a melhoria econômica-social dos cooperados e a manutenção da própria organização a partir de regras inerentes à democracia.

\section{O Modelo OADI-SMM de Daniel H. Kim}

O modelo OADI-SMM (KIM, 1993) contempla o compartilhamento da aprendizagem nas organizações, onde o autor se preocupa com o chamado "Elo de Ligação" entre indivíduo e organização no processo da aprendizagem, sendo que para tanto desenvolve analogias, partindo do pressuposto de que a aprendizagem da organização dependeria de componentes similares aos da individual, como memória e modelos mentais da aprendizagem no nível organizacional realizando analogias com a aprendizagem individual.

O ponto de partida do modelo é a constatação de que uma organização aprende através de seus membros individuais (ARGYRISeSCHÖN, 1978). Sendo assim, para se entender a Aprendizagem Organizacional seria necessário estudar a aprendizagem individual e desenvolver uma teoria sobre o processo de como a aprendizagem individual transforma-se em organizacional - de como inserir o conhecimento na memória e na estrutura da organização. Kim (1993) propôs como solução a junção do modelo de aprendizagem experiencial de Kofman, adaptado de Lewin, com o Modelo Mental Individual derivado de Senge, mais um mecanismo de transferência que ele denominou Modelos Mentais Compartilhados, envolvendo o Modelo de Aprendizagem de March e Olsen, dotando-o ainda com os circuitos simples e duplo de Argyris. Kim (ibidem) define a aprendizagem individual como a aprendizagem que se desenvolve com base na experiência, na observação e na capacidade que o

REGET - V. 20, n. 1, jan.- abr. 2016, p. 86-96 
Royer et al.: O processo de aprendizagem organizacional em central cooperativa agroindustrial

indivíduo possui para refletir e avaliar situações, criando estruturas cognitivas, modelos interpretativos e rotinas de trabalho.

O modelo OADI-MM consiste de um ciclo de aprendizagem composto de observar-avaliarprojetar-implementar, onde as pessoas vivenciam eventos concretos, avaliam sua experiência pela reflexão sobre suas observações, projetam um conceito abstrato em resposta à avaliação e implementam-no, o que provoca uma nova experiência concreta, iniciando outro ciclo. Kim (ibidem) propõe que as fases implementar e observar compõem a aprendizagem operacional: as pessoas aprendem como fazer (know-how) enquanto que as fases avaliar e projetar definem a aprendizagem conceitual: as pessoas compreendem e aplicam o conhecimento (know-why).

Para Kim (ibidem, p. 38) a aprendizagem é a "aquisição de conhecimentos ou habilidades (...) crescente habilidade de um indivíduo em tomar ações efetivas" que consiste, primeiro, na aquisição de habilidades ou know-how e, segundo, na aquisição de know-why, capacidade de articular conceitualmente uma compreensão a partir de experiências.

Segundo o Kim (ibidem), as duas dimensões são importantes, procura mostrar a ligação implícita entre ação e pensamento (experiência e conhecimento), pois, para o autor, não seria suficiente adquirir apenas um conhecimento para a ação (know-how) como forma efetiva para utilizar habilidades sem compreender os conceitos e a coerência das estruturas de pensamento (know-why). Assim como, no sentido inverso, o know-why não permite a ação, dependente operacionalmente das regras do knowhow. Isto, ocorre também na organização e não apenas no nível individual, porém, com um processo diferente, porque no individual há uma inter-relação entre a observação, a avaliação, a projeção e a implementação com a memória dinâmica que tem uma forma especial denominada como modelos mentais nas pessoas.

Para que a aprendizagem individual possa ser armazenada, a proposta de Kim é adicionar o conceito de Modelos Mentais (memória ativa) ao OADI-MM. Modelos mentais são imagens internas de como o mundo funciona (SENGE, 1990), são as visões pessoais de como o mundo é, fornecendo o contexto para observar e interpretar novas informações, assim, Modelos Mentais Individuais seriam compostos de Estrutura e de Rotinas (KIM, 1993). Neste escopo, na aprendizagem operacional o know-how é armazenado nas rotinas que por sua vez também afetam a própria aprendizagem operacional. Já na aprendizagem conceitual, o know-why interage com a segunda parte dos modelos mentais - as novas estruturas, que permitem repensar o problema de forma diferente.

À semelhança dos Modelos Mentais Individuais e relacionando-se com ele, Kim (ibidem) agregou os Modelos Mentais Compartilhados, substituindo Estruturas por weltanschauung, definida como a forma com que a organização interpreta as respostas ambientais, se agirá sobre elas e que meios específicos empregará se decidir agir. A weltanschauung seria um reflexo da cultura, suposições arraigadas, regras de comportamento e artefatos da organização.

O modelo integrado de aprendizagem organizacional proposto por Kim (ibidem), engloba a noção de modelos mentais e o modelo experiencial da aprendizagem. A noção de modelos mentais cria uma síntese entre as crenças compartilhadas em um grupo e as que são inerentes aos indivíduos, representam o que foi aprendido. O compartilhamento de modelos mentais se dá por contribuição das aprendizagens individuais, onde as regras não tangíveis podem orientar ações, indo além da memória organizacional, que está restrita às rotinas formais/escritas. Não são apenas repositórios de informações, os modelos mentais integram processos ativos para a formulação de teorias que interferem na ação. Para Kim (ibidem) os modelos mentais estão contidos numa weltanschauung da organização (cultura organizacional), que é pouco tangível, pois envolvem crenças, valores, e senso comum.

Para Kim (apud BASTOS, GONDIM, LOIOLA, MENEZES e NAVIO, 2002), a aprendizagem toma forma de organizacional no momento em que esses modelos interpretativos e rotinas deixam de ser individuais e passam a ser compartilhados pelos membros da organização.

Assim, passa a existir aprendizagem organizacional no momento em que a organização tem a capacidade de disseminar e favorecer o compartilhamento de estruturas cognitivas e de modelos interpretativos e, por conseguinte, é capaz de criar uma unidade de entendimento com um significado mais ou menos comum acerca dos eventos que ocorrem nesse contexto.Se acompanharmos as argumentações que sinalizam a passagem do 
Royer et al.: O processo de aprendizagem organizacional em central cooperativa agroindustrial

\begin{abstract}
plano individual da aprendizagem para o plano organizacional, parece ser hegemônica a noção de que a aprendizagem passa a ser organizacional no momento em que, transcendendo a cada indivíduo em particular, conhecimentos, atitudes, visões e práticas passam a ser compartilhados pelo coletivo. Este compartilhamento pode levar à criação de estruturas ou rotinas que tornam explícitas novas formas de agir na organização. Neste sentido, os processos de aprendizagem organizacional guardam estreita correlação (e talvez se sobreponham) aos processos de difusão e socialização. Assim, podemos concluir que o eixo central estaria na criação de processos de comunicação e espaços apropriados, que permitam as trocas de experiências, significados, crenças e valores individuais, o que auxiliaria na construção de modelos compartilhados (BASTOS, GONDIM, LOIOLA, MENEZES e NAVIO, 2002, p.5)
\end{abstract}

Por fim, Kim (1993) apresenta a possibilidade de rupturas no processo de aprendizagem no que ele chama de Ciclos de Aprendizagem Incompletos, que poderiam dificultar ou até impedir a aprendizagem organizacional. Ao todo seriam sete pontos críticos de desconexão, sendo quatro idealizados por March e Olsen e três desenvolvidos pelo próprio autor.

O indivíduo age com base em suas convicções individuais (MARCHeOLSEN, 1975), a ação individual influenciará o agir da organização que, por sua vez, implicará em uma resposta ambiental a ser captada pelo indivíduo alterando suas convicções mentais, a partir daí poderia se estabelecer um novo ciclo de aprendizagem com um novo agir individual caso fosse embasado nas novas convicções individuais auferidas no ciclo anterior. Assim, a cada resposta ambiental diferente o indivíduo altera sua convicção, uma resposta ambiental que não seja diferente à esperada pelo indivíduo implica em uma manutenção das convicções individuais e, portanto, uma não alteração no agir individual e da organização, em consequência.

Apesar de parecer complexo, o modelo OADI-SMM apresenta três elementos centrais: a aprendizagem da organização; a aprendizagem do indivíduo, e; o compartilhamento da aprendizagem entre os dois outros elementos. Em relação ao modelo, o olhar sobre o processo de aprendizagem organizacional pode acontecer sob a perspectiva da organização ou do indivíduo, a abordagem simultânea, apesar de não ser impossível, demandaria muito esforço em termos de tempo de campo e capacidade do pesquisador.

Os quatro pontos críticos de desconexão idealizados por March e Olsen (1975) estão presentes no modelo de Kim (1993), os quais são: aprendizagem limitada pelo papel; aprendizagem limitada pela audiência; aprendizagem supersticiosa, e; aprendizagem com ambiguidade.

Kim transportou integrou o Modelo de Aprendizagem Organizacional de March e Olsen ao OADISMM, aproveitando inclusive esses possíveis pontos de ruptura, que valem ser detalhados: Aprendizagem Limitada pelo Papel acontece quando a aprendizagem do indivíduo não afeta seu agir por impedimento de sua função, não seria de sua alçada implementar ou não teria autonomia para agir naquele sentido ou situação; Aprendizagem pela Audiência ocorre quando a organização é afetada de forma ambígua pelo agir do indivíduo; Aprendizagem Supersticiosa quando não existe uma lógica ou base real em relação ao que a organização ou o indivíduo está fazendo com a resposta ambiental que está se obtendo, a organização faz uma coisa e o ambiente entende/assimila outra; Aprendizagem com Ambiguidade quando o indivíduo age afetando a organização e o ambiente, contudo, não existe uma conexão causal entre os episódios do agir, ou seja, acontece a aprendizagem operacional, porém, não ocorrendo a conceitual, um equilíbrio entre as duas seria determinante para uma aprendizagem organizacional eficaz.

Por fim, os pontos de ruptura idealizados por Kim (ibidem), os quais interrompem o ciclo completo de aprendizagem e podem impedir o processo de aprendizagem da organização, são: Aprendizagem Supersticiosa quando não existe uma lógica ou base real em relação ao que a organização ou o indivíduo está fazendo com a resposta ambiental que está se obtendo, a organização faz uma coisa e o ambiente entende/assimila outra; Aprendizagem Situacional acontece quando o indivíduo não consegue guardar o que aprendeu ou não consegue codificar a aprendizagem, impossibilitando o aproveitamento da mesma no futuro, estabelece-se assim uma ruptura entre a aprendizagem e os modelos mentais do indivíduo, ou seja, impossibilita-se a aprendizagem individual de duplo loop (IDLL), mesmo que ela tenha acontecido nos níveis operacional e conceitual. A consequência para a organização é o não aproveitamento da aprendizagem em longo prazo; Aprendizagem Fragmentada

REGET - V. 20, n. 1, jan.- abr. 2016, p. 86-96 
Royer et al.: O processo de aprendizagem organizacional em central cooperativa agroindustrial

quando apesar do indivíduo aprender operacional e conceitualmente, transferir sua aprendizagem para seus modelos mentais e modificar suas estruturas e rotinas, na aprendizagem fragmentada a organização não consegue se apropriar da aprendizagem individual, assim, caso o indivíduo venha a se desligar da organização, a organização poderá vir a perder esta aprendizagem; Aprendizagem Oportunística ocorre quando o agir organizacional não segue os procedimentos ou significados compartilhados na organização, assim, uma ação isolada em prol de um benefício ou na tentativa de contornar uma crise momentânea, não será assimilada pela organização e não poderá ser replicada ou reaproveitada no futuro por outros indivíduos.

\section{Aspectos metodológicos}

O estudo pode ser caracterizado como pesquisa social, apresentando caráter descritivo numa abordagem qualitativa. Trata-se de uma produção científica com o objetivo principal de analisar o processo da aprendizagem organizacional em central cooperativa agroindustrial à luz do modelo OADI-SMM, sob a perspectiva da organização tendo o cooperado como indivíduo.

A estratégia adotada foi o Estudo de Caso, a qual está associada à técnica de métodos qualitativos, portanto, não se pretende ou se pode generalizar os resultados para outras populações, sequer esperase alcançar a representatividade amostral, em relação à lei da probabilidade. Segundo Yin (2004), a estratégia é apropriada quando se analisa fenômenos contemporâneos no mundo real e quando os eventos não podem ser controlados, é aplicável nas situações quando se quer manter as características holísticas e significativas dos eventos, ou seja, quando se entende que o contexto é pertinente ao fenômeno em estudo, no caso dos processos administrativos e organizacionais.

Porém, do ponto de vista científico, buscou-se dar profundidade aos materiais, à interpretação, à contextualização, aos detalhes e às experiências diferenciadas, assim como cabe, em relação à população, a informação de que a Cooperativa Central conta com cinco cooperativas afiliadas, que são suas controladoras ou proprietárias, quatro delas suas fundadoras; as cinco cooperativas afiliadas contam com, aproximadamente, 30.000 cooperados, que são seus proprietários.

Em termos de instrumentos para coleta de dados, adotou-se exclusivamente a Entrevista Não Diretiva. As entrevistas foram gravadas e, posteriormente, transcritas para análise buscando-se detalhar as atividades, sendo que na primeira fase realizou-se uma coleta inicial de materiais destinada ao entendimento da organização, voltada basicamente à visão sistêmica, sob o prisma do sistema cooperativo, buscou-se levantar materiais primários por meio de entrevistas não diretivas com os seguintes atores: (i) diretor presidente da cooperativa central; (ii) diretor executivo da cooperativa central; (iii) diretor vice-presidente da cooperativa afiliada com maior participação de negócios junto à cooperativa central; (iv) gestora de relacionamento com o quadro social da cooperativa afiliada com maior participação de negócios junto à cooperativa central; (v) diretor secretário da cooperativa afiliada com a segunda maior participação de negócios junto à cooperativa central; (vi) gestora de relacionamento com o quadro social da cooperativa afiliada com segunda maior participação de negócios junto à cooperativa central; e, (vii) gestor de relacionamento com o quadro social de uma terceira cooperativa afiliada à cooperativa central.

Numa segunda fase efetuou-se coleta de materiais para aprofundar as informações e percepções apuradas na primeira fase em relação a um exemplo específico de aprendizagem organizacional, mediante entrevistas não diretivas com: (viii) gerente de unidade responsável pelo atendimento comercial aos cooperados da cooperativa afiliada com maior participação de negócios junto à cooperativa central; (ix) encarregado da área técnica responsável pelo atendimento técnico e repasse de tecnologia aos cooperados da mesma cooperativa afiliada; e, (x) cooperado que tenha participado do processo de aprendizagem da mesma cooperativa afiliada, para obter sua percepção e para balizar a análise, uma vez que o estudo foi delimitado sob a perspectiva da organização

O processo de apresentação, análise e interpretação de materiais consistiu em extrair sentido dos materiais de transcritos obtidos a partir do material original gravado durante as entrevistas realizadas. Neste estudo, para a análise de conteúdo, adotou-se o método proposto por Moraes (1999), cujas 
Royer et al.: O processo de aprendizagem organizacional em central cooperativa agroindustrial

atividades se desenvolveram em cinco etapas: a preparação; a unitarização; a categorização; a descrição, e; a interpretação.

\section{OADI-SMM e a aprendizagem cooperativista}

Para inovar de maneira incremental suas rotinas e seus negócios, a organização cooperativista parece adaptar e desenvolver a eficiência organizacional através de uma melhor utilização dos seus recursos humanos (DOGSON, 1993) quando designam os técnicos para participarem e atenderem aos cooperados nas reuniões dos núcleos cooperativo, que têm suas pautas estabelecidas pelos cooperados e cumpridas pelos gestores e técnicos das cooperativas afiliadas e da cooperativa central, num esforço para viabilizar a integração dos conhecimentos armazenados na memória dos cooperados e o conhecimento disponível nas áreas operacionais/técnicas da cooperativa (SIMON, 1997). Os técnicos participam destes núcleos para o fomento à produção de carne suína e leite, industrialização na cooperativa central de seus derivados e disponibilização por ela de produtos com alto valor agregado em pontos de venda no mercado nacional e internacional. Nas reuniões do núcleo a discussão gira em torno de comercialização, importação, exportação, perspectivas de mercado, lucratividade e investimentos, sendo que as deliberações são divulgadas para todos os cooperados por meio de informativos impressos e programas de rádio, principalmente. Estes momentos demonstram de forma prática que:

\footnotetext{
...a competência individual tem íntima ligação com as competências organizacionais e consequentemente com o sucesso da estratégia, na maior parte dos casos. A articulação de recursos, chave do processo, é totalmente dependente da competência individual em realizá-la. Portanto, a articulação e a rearticulação de recursos perante as demandas, passando por um processo de aprendizado, tendem a conduzir para uma facilitação da aquisição, da legitimação e do reconhecimento da competência (Musetti Munck \& Munck, 2008, p.72).
}

No sistema, cada cooperado (indivíduo) representa uma família cooperada gestora de uma unidade produtora agropecuária. É preciso considerar que estes indivíduos têm seus modelos mentais próprios desenvolvidos em função de sua capacidade de aprendizagem, ou seja, sua capacidade conceitual (avaliar e projetar) e operacional (implantar e observar) para aprender e de sua capacidade de estabelecer, desenvolver e recorrer a seus próprios modelos mentais individuais. A integração e aproveitamento da aprendizagem individual e dos modelos mentais no cooperado (Figura 1) podem ser caracterizados como Individual Double-Loop Learning (IDLL) que está contemplada no modelo OADI-SMM de Kim (1993).

O cooperado é o principal responsável pelo estabelecimento de seus modelos mentais, ele não recebe conhecimento passivamente (CONKLIN, 1996), porém outros agentes externos colaboram e até procuram conduzir o estabelecimento de rotinas e estruturas que compõem os modelos mentais dos cooperados, o que geralmente se dá a partir de esforços de capacitação e aperfeiçoamento por parte destes agentes que seriam: a própria organização cooperativista; fornecedores de insumos, equipamentos e tecnologia; institutos ambientais governamentais; sistemas de aprendizagem rural como o SESCOOP e outros integrantes ou não do sistema cooperativista, como o SENAR; entidades de pesquisa privadas e de organizações governamentais; entidades do terceiro setor, e: ONG's voltadas à sustentabilidade ambiental e valorização do profissional ou empreendedor do campo.

A organização cooperativista, como os demais agentes, conta com cultura e rotinas organizacionais próprias que procura disseminar ou das quais se vale para influenciar ou colaborar com o desenvolvimento dos modelos mentais individuais dos cooperados. Quando a organização cooperativista, além de colaborar ou influenciar, se apropria dos modelos mentais de um cooperado e dissemina aos demais, segundo Kim (1993), pode-se dizer que a organização cooperativista está promovendo a disseminação da aprendizagem e que está acontecendo a aprendizagem organizacional (Figura 1), por meio do compartilhamento dos significados.

Ainda segundo o autor, esta apropriação e disseminação pode ser chamada de Organizational Double-Loop Learning (ODLL) e está contemplada no modelo OADI-SMM de Kim (1993). No modelo 
proposto por Kim (ibidem), o qual suporta teoricamente a simulação aqui apresentada, esta aprendizagem leva a uma ação organizacional da cooperativa, que vai depender inevitavelmente da ação individual do cooperado, acarretando em resultados, que o autor denomina como respostas ambientais, que serão observadas (tanto a ação organizacional quanto a individual) pelo cooperado e/ou pelos demais colaboradores da organização (Figura 1).

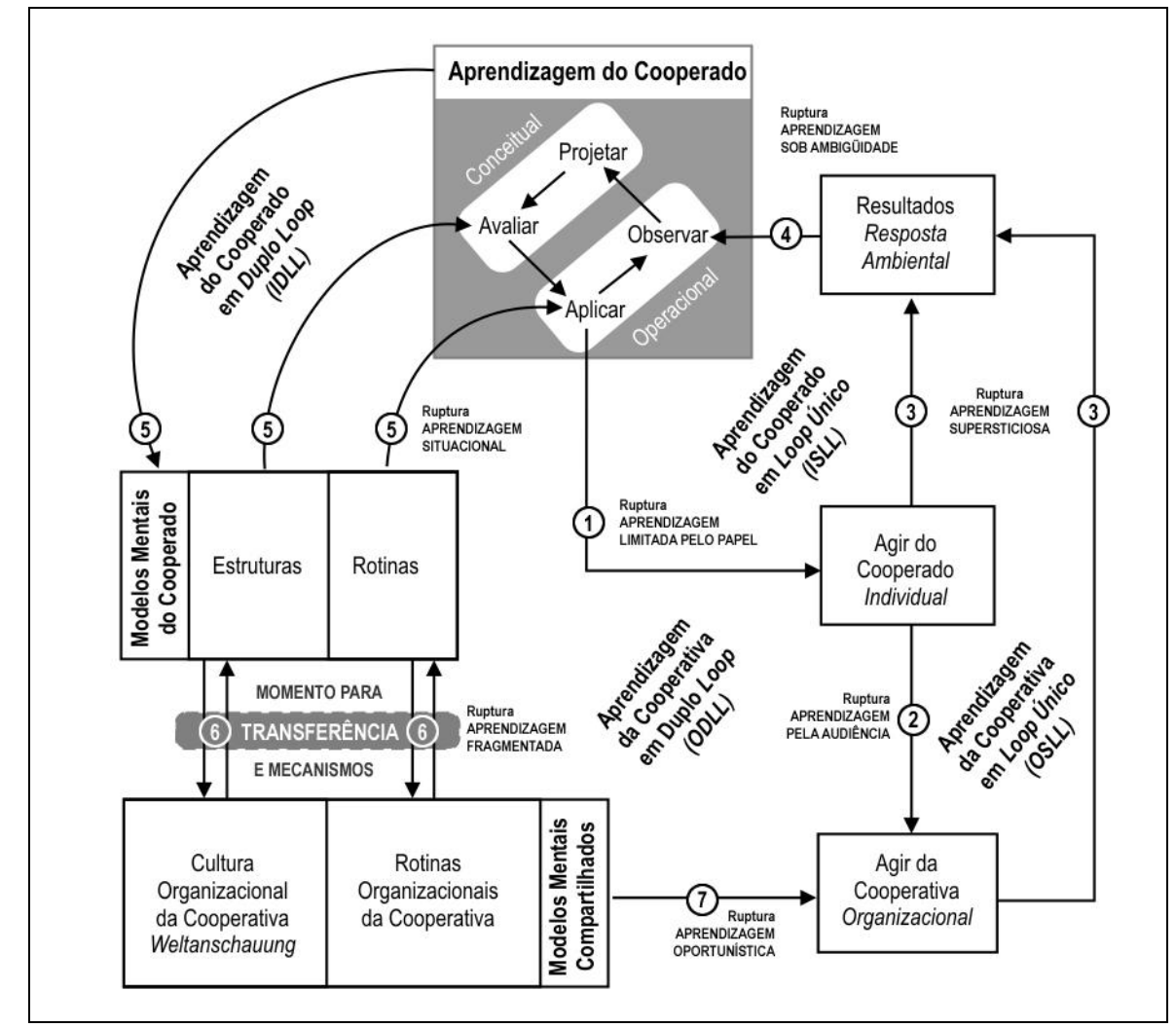

Figura 1 - Ciclo OADI-SMM-COOP.

Fonte: adaptado de Kim (1993)

A capacidade operacional do cooperado em observar estes resultados vai tornar a alimentar seu sistema de aprendizagem individual, que por sua vez se estabelecerá nos modelos mentais individuais (Figura 1) e que poderão ser apropriados pela organização cooperativista e que se apropriados e disseminados estarão realimentando a aprendizagem organizacional e desencadeando um novo ciclo. A capacidade do cooperado agir individualmente e aprender seria segundo o modelo a Individual Single-Loop Learning (ISLL), a capacidade de a partir da ação do cooperado a organização cooperativista aprender se denominaria Organizational Single-Loop Learning, isto de forma estanque ou isolada.

A proposta de um modelo integrado (Figura 1) se dá a partir de três momentos: o cooperado internaliza a aprendizagem gerada pela ação para os seus modelos mentais; a organização cooperativista internaliza a mesma aprendizagem para a cultura e rotinas organizacionais (weltanschauung), e; a organização cooperativista se apropria do modelo mental do cooperado, aperfeiçoa ou complementa sua cultura e rotinas organizacionais e promove a disseminação da aprendizagem, onde poderia acontecer ou não o compartilhamento de modelos mentais entre a organização e o indivíduo. Na organização cooperativista o desenvolvimento se dá mediante o processamento das informações de forma compartilhada o que tem modificado a extensão do comportamento potencial, pois, ao que parece, os cooperados adquirem conhecimento que consideram úteis para sua propriedade e para a cooperativa como um todo, inclusive se envolvem na aquisição de conhecimento, na interpretação e socialização de informações, colaborando diretamente com a formação da memória e da cultura organizacional (HUBER, 1991). 
Royer et al.: O processo de aprendizagem organizacional em central cooperativa agroindustrial

Este compartilhamento, Kim (ibidem) denomina como o "O Elo de Ligação" e que na adaptação do modelo desenvolvida pelos autores deste, a qual está apresentada como Ciclo OADI-SMM-COOP, aparece sob nome "Transferência" (Figura 1), representando o momento em que pode ocorrer o compartilhamento da aprendizagem entre o cooperado no papel de indivíduo, subgrupos representados pelos núcleos e conselhos e a cooperativa enquanto organização (CROSSAN, LANE, WHITEeDJURFELDT, 1995), neste momento é que aconteceria o partilhar dos significados e, talvez, seja o principal elemento colaborador na perenidade e competitividade da organização frente às mudanças do ambiente, caracterizando sua constante busca pela melhora do desempenho (TSANG, 1997).

Nas três décadas de atuação, indica-se que tenha conseguido acumular os conhecimentos e reivindicações em toda a cadeia vertical envolvida na gestão/operacionalização de seus negócios, especialmente junto aos produtores através das cooperativas afiliadas, estimulando os indivíduos e os subgrupos a colaborarem com a organização no sentido de buscar a discussão e proposição de soluções para seus desafios (SIMON, 1969) seguindo a lógica do "Ciclo de Aprendizagem para Formulação de Estratégias e Formação de Competências" de Musetti Munck e Munck (2008, p. 72), pelo qual:

\footnotetext{
Inicialmente, a organização identifica seus recursos ou a falta ou o excesso destes. Em seguida, ela trabalha no preenchimento de lacunas, se houver, e depois na articulação, a fim de constituir ou identificar competências. Com base nas competências identificadas, estuda-se a melhor estratégia a ser utilizada. Na execução da estratégia, a aprendizagem ocorre por meio de erros, acertos, carências e sobras, no que se refere a recursos e competências. Consequentemente, desencadeia-se um processo de mudança para adquirir, aprimorar ou corrigir os recursos e as competências.
}

Também, nesta análise, são possíveis algumas considerações em relação aos possíveis constrangimentos que poderiam vir a surgir no sistema e que poderiam levar a uma ruptura parcial do processo de aprendizagem, ou até o seu total impedimento, em decorrência de Aprendizagem pela Audiência ou Supersticiosa ou Oportunística ou Fragmentada.

O sistema pode levar a uma Aprendizagem pela Audiência (marcador 2 na Figura 1) quando o desinteresse de um cooperado em relação a participação na gestão ou seus interesses pessoais em relação a vantagens de condições comerciais junto a organização poderia levar, o mesmo, a apresentar feedbacks, consciente ou inconscientemente, que não corresponderiam a sua real expectativa ou intenção, outra possibilidade seria que o colaborador responsável pelo contato com o cooperado, seja da área técnica, nas unidades ou até seu coordenador de núcleo, poderia entender/filtrar de forma equivocada estes feedbacks.

Também, identifica-se a possibilidade de uma Aprendizagem Supersticiosa (marcador 3 na Figura 1) caso a organização ao estabelecer estratégias que demandassem mudanças operacionais drásticas, tendo como razão uma visão do macro ambiente que justificaria o esforços, mas que depois de mudar todo o agir da organização e dos indivíduos a resposta do ambiente não correspondesse às expectativas, um possível exemplo seria o caso de investir-se na ideia de melhoria da qualidade do produto em função de que o mercado estaria exigindo e a capacitação das pessoas, remuneração dos prestadores de serviço e fornecedores de matéria - prima, assim como os investimentos na produção e comercialização permanecessem voltados à produção em escala.

A Aprendizagem Oportunística (marcador 7 na Figura 1) poderia se apresentar quando a organização opta por abandonar uma estratégia vigente, mantendo toda a operação e justificativa de negócios, para atingir resultados que não foram compartilhados com toda a organização previamente, poderia ser o caso do exemplo anterior, em que a organização apesar estar dirigida à qualidade do produto, opta-se por trabalhar em economia de escala, de forma consciente, a fim de aproveitar um momento de alta procura no mercado, por exemplo, ou a fim de assegurar que grandes fornecedores de matéria-prima continuem suprindo o sistema.

Outra possibilidade, seria a Aprendizagem Fragmentada (marcador 6 na Figura 1) que afetaria totalmente a organização cooperativista em função de que sua composição está ancorada na 
Royer et al.: O processo de aprendizagem organizacional em central cooperativa agroindustrial

participação dos cooperados, ainda que em tese, nesta situação a organização não conseguiria se apropriar da aprendizagem de seus cooperados, significando que se algum cooperado abandonasse a cooperativa levaria com ele todo o expertise de um processo de produção ou capacidade de gestão ou, ainda, força política interna com cooperados/externa com a comunidade e outras organizações.

\section{Conclusões}

Considerando as principais premissas decorrentes da análise do processo da aprendizagem organizacional na central cooperativa, realizadas neste estudo à luz do modelo OADI-SMM, o constructo do estudo sob a perspectiva da organização tendo o cooperado como indivíduo, possibilita compreender a partir do marco teórico adotado os principais conceitos sobre aprendizagem organizacional e o modelo OADI-SMM.

Também, apresentam-se na revisão teórica as peculiaridades das organizações cooperativistas no agronegócio e suas principais características de gestão, as quais puderam ser comparadas, por meio das entrevistas diretivas, ao processo da aprendizagem organizacional na central cooperativa, bem como, conhecer seus principais mecanismos, agentes e momentos.

Em termos de impressões finais sobre o processo de aprendizagem organizacional na unidade de estudo, a análise e interpretação de materiais realizada permite afirmar que a central cooperativa agroindustrial, à luz do modelo OADI-SMM de Kim (1993), consegue promover a transferência da aprendizagem entre o indivíduo cooperado e a organização cooperativa por meio do partilhar dos significados nos momentos de encontros nos subgrupos representados pelos núcleos e conselhos cooperativistas, nos quais a constante busca pela melhora do desempenho apresenta-se como principal elemento colaborador na perenidade e competitividade da organização frente às mudanças do ambiente.

Conclui-se também, que o processo da aprendizagem organizacional na unidade de estudo está alinhada aos precursores da matéria: Cyert e March; Cangelosi e Dill, e; Argyris e Schön.

Primeiro, a unidade de estudo tem ao longo do tempo desenvolvido e fortalecido contínua e endemicamente os seus mecanismos de aprendizagem organizacional (ARGYRISeSCHÖN, 1978), por estar por estar econômica, política e tecnologicamente inserida em ambientes instáveis.

Segundo, conscientemente ou não em relação a importância da aprendizagem organizacional, a organização tem conseguido promover troca de conhecimento adquirido nas adaptações ao ambiente(CANGELOSIeDILL, 1965), desenvolvidas ou vivenciadas seja pelos cooperados, pelos núcleos, pelas cooperativas afiliadas e pela própria central, como forma de fazer frente à complexidade do agronegócio, incerteza sobre o futuro, e incentivos inadequados vigentes no setor.

Terceiro, pode-se conjecturar que enquanto organização a central cooperativa realmente aprende, pois, apresenta um comportamento adaptativo durante sua existência(CYERTeMARCH, 1963), no qual os cooperados e as cooperativas afiliadas têm conseguido auferir melhorias, que são aproveitadas pela cooperativa central para construir sua própria aprendizagem.

Como em todo estudo de caso, não se procurou entender o por que e tampouco as causas ou as consequências em relação ao fenômeno, assim, a principal restrição do estudo é o fato de que o processo de aprendizagem em uma organização cooperativista, enquanto um sistema social, envolve uma complexidade dinâmica, por isso, as reações e consequências observadas reportam-se apenas ao período da pesquisa e não podem ser avaliadas suas consequências para o comportamento, seja dos indivíduos, do grupo ou da organização além do período em que ocorreu o estudo.

\section{Referências}

ARGYRIS, C.; SCHÖN, D.A. Organizational learning: a theory of action perspective. Massachusetts: Addison-Wesley Publishing Company, 1978.

BASTOS, A.V.B.;GONDIM, S.M.G.;LOIOLA, E.;MENEZES, I.G.; NAVIO, V.L.R. Aprendizagem Organizacional versus Organizações que Aprendem: Características e Desafios que cercam essas duas Abordagens de Pesquisa. In ENCONTRO DE ESTUDOS ORGANIZACIONAIS, 2., 2002, 
Royer et al.: O processo de aprendizagem organizacional em central cooperativa agroindustrial

Recife. Anais... Recife: Observatório da Realidade Organizacional : PROPAD/UFPE : ANPAD, 2002. 1 CD

CANGELOSI, V.E.; DILL, W.R.Organizational learning: observations toward a theory. Adminstrative Science Quarterly, 10(2), 1965.

CHADAD, F.R. Cooperativas no agronegócio do leite: mudanças organizacionais e estratégicas em resposta à globalização. In Organizações Rurais $\mathcal{E}$ Agroindustriais, Lavras, v. 9, n. 1, p. 69-78, 2007.

CONKLIN, E. J. Capturing organizational memory. Group Decision Support Systems, 1996. Disponível em: <http://www.welchco.com/02/14/01/60/96/01/0103.HTM >. Acesso em: 24jun. 2015.

COOK, M.L. The future of U.S. Agricultural Cooperatives: a neo-institutional approach. In American Journal of Agricultural Economics, [S.1.], v. 77, n. 5, p. 1153-1159, 1995.

CROSSAN, M.M.;LANE, H.W.;WHITE, R.E.;DJURFELDT, L.Organizational learning: dimensions for a theory. InThe International Journal of Organizational Analysis, Bowling Green, v. 3, n. 4, p. 337-360, 1995.

CYERT, R.;MARCH, J. A behavioral theory of the firm. Englewood Cliffs, NJ: Prentice-Hall, 1963.

DOGSON, M. Organizational learning: A review of some literatures. Organization Studies, v. 21, n. 5, p. 375-394, 1993.

GHEMAWAT, P. Commitment: the dynamic of strategy. New York: Free Press, 1991.

HUBER,G.P. Organizational learning: the contributing processes and the literature. In Organization Science, 2 (2):88-115,1991.

KIM, D.H. The link between individual and organizational learning. Sloan Management Review. [ ], out 1993. p. 37-50.

O elo entre a aprendizagem individual e a aprendizagem organizacional. In Klein, D. (org). $A$ gestão estratégica do capital intelectual: recursos para a economia baseada em conhecimento. Rio de Janerio: Qualitymark, 1998.

LAUSCHNER, R. Agribusiness, cooperativa e produtor rural. 2. ed. São Leopoldo: Unisinos, 1995.

LEONARD-BARTON, D. Core capabilities and core rigidities: a paradox In managing new product development. In Strategic Management Journal, 13, p. 111-125, 1992.89.

MARCH, J.G.; OLSEN, J.P. The uncertainty of the past: organizational learning underambiguity. European Journal of Political Research, v. 3, p. 141-171, 1975.

MORAES, R. Análise de conteúdo. In Revista Educação, Porto Alegre, v. 22, n. 37, p. 7-32, 1999.

MUSETTI MUNCK, M.G.; MUNCK, L. Gestão organizacional sob a lógica da competência: aplicação na pequena empresa. RAM. Revista de Administração Mackenzie (Impresso), v. 9, p. 25-39, 2008

PEDROZO, E.A. Análise de Cooperativas Agrícolas através da Utilização de Estratégias Industriais. In ANAIS - ENCONTRO NACIONAL DA ANPAD, 1993, Salvador - Bahia, Curitiba - Paraná, 27 a 29 de setembro de 1993, p.10-13.

POLÔNIO, W.A. Manual das sociedades cooperativas. São Paulo: Atlas, 1999.

POWELL, W.W. Neither market nor hierarchy: network forms of organizations. Research In Organizational Behavior, v.12, p.295-336, 1990.

SENGE, P. A quinta disciplina: arte e prática da organização de aprendizagem. São Paulo: Best Seller, 1990.

SIMON, H.A. Sciences of the artificial. Cambridge, MA: MIT Press, 1969.

Administrative behavior: A study of decision-making processes in administrative organizations. (4th ed.). New York: The Free Press, 1997.

TSANG, E.W.K. (1997). Organizational learning and the learning organization: A dichotomy between descriptive and prescriptive research. Human Relations, 59(1), 73-89.

WAACK, R.S.;MACHADO FILHO, C.P.M. Administração estratégica em cooperativas agroindustriais. In , 2, 1999, Ribeirão Preto.

YIN, R. Estudo de caso. 2ª edição. Bookman. Porto Alegre, 2004. 